\title{
DESAIN DAN ANALISIS INVERTER SATU FASA BERBASIS ARDUINO MENGGUNAKAN METODE SPWM
}

\author{
David Setiawan ${ }^{1}$, Hamzah Eteruddin ${ }^{2}$, Arlenny $^{3}$ \\ ${ }^{123}$ Prodi Teknik Elektro, Fakultas Teknik, Universitas Lancang Kuning \\ ${ }^{1}$ dsetia@unilah.ac.id, ${ }^{2}$ hamzah@unilak.ac.id, ${ }^{3}$ arlenny@unilak.ac.id
}

\begin{abstract}
ABSTRAK
Inverter adalah rangkaian atau peralatan yang merubah tegangan DC menjadi tegangan AC sehingga beban - beban AC dapat beroperasi dengan sumber tegangan DC. Komponen utama inverter berupa SCR, transistor atau Mosfet yang kesemuanya adalah komponen semikonduktor yang berfungsi sebagai switch atau saklar. Kondisi ON atau OFF dari saklar ditentukan menggunakan teknik modulasi seperti pembangkit pulsa atau PWM. Dalam simulasi yang dilakukan menggunakan Proteus ISIS, inverter 1 fasa yang tidak diberi pengendali menghasilkan frekuensi yang tinggi yaitu 2857,14 Hz sehingga berbahaya digunakan pada peralatan listrik tertentu, sedangkan inverter 1 fasa menggunakan kendali untuk membangkitkan pulsa dengan metode PWM menghasilkan frekuensi output sesuai dengan apa yang diharapkan yaitu 50hz dengan delay $10 \mathrm{~ms}$ waktu perubahan pulsa yang dihasilkan. Pulsa atau PWM dihasilkan oleh Arduino Uno.
\end{abstract}

Kata kunci : Inverter, Arduino Uno, Pembangkit Pulsa, SPWM

\begin{abstract}
Inverter is a circuit or equipment that converts $\mathrm{DC}$ voltage into AC voltage so that $\mathrm{AC}$ loads can operate with a DC voltage source. The main components of the inverter are SCR, transistor or Mosfet, all of which are semiconductor components that function as switches. The ON or OFF conditions of the switch are determined using a modulation technique such as a pulse generator or PWM. In simulations carried out using ISIS Proteus, 1 phase inverters which are not given a controller produce a high frequency of $2857.14 \mathrm{~Hz}$ so that it is dangerous to be used in certain electrical equipment, whereas 1 phase inverters use controls to generate pulses with the PWM method producing an output frequency in accordance with what expected is $50 \mathrm{hz}$ with a delay of $10 \mathrm{~ms}$ when the pulse change generated. Pulses or PWM are generated by Arduino Uno..
\end{abstract}

Keywords: Inverter, Arduino Uno, Generate Pulse, SPWM

\section{PENDAHULUAN}

Dunia elektronika terus mengalami kemajuan atau perkembangan di berbagai bidang, perubahan tersebut tentu saja dapat merubah cara atau pola kehidupan manusia menjadi lebih mudah. Dengan kemajuan dibidang elektronika ini, perubahan terhadap bidang lainnya juga ikut berkembang seperti sumber energi listrik. Ada beberapa faktor yang mempengaruhi kemajuan elektronika dan juga dapat mempengaruhinya seperti perkembangan peralatan elektronika yang semakin 
beragam saat ini. Inverter adalah alah satu peralatan elektronika yang berfungsi sebagai perubah tegangan DC menjadi tegangan AC. Penggunaan inverter baik di rumah, dikendaraan atau di kantor dimanfaatkan sebagai penyedia listrik cadangan seperti emergency power dimana aliran listrik dari PLN tidak menyalurkan energi karena gangguan ataupun pemeliharaan. Inverter terdapat dalam peralatan rumah tangga seperti lampu, komputer, TV, kipas angin hingga keperalatan pertukangan seperti gerinda, bor dan lainnnya dimana sistem atau sumber suplai tenaga listrik di daerah terpencil sehingga inverter bermanfaat dalam kebutuhan kehidupan sehari-hari sebagai alternatif energi listrik di daerah terpencil atau disaat sumber listrik seperti PLN padam pada malam hari.

Listrik adalah energi yang paling fleksibel dalam penggunaannya serta termasuk energi berbiaya murah dalam penggunaannya. Pemanfaatan sumber energi listrik terbarukan seperti panel surya, kincir dan sebagainya yang memiliki tegangan output yang sangat kecil dan tidak dapat dihubungkan langsung kepada peralatan listrik terlebih dahulu harus dikonversikan sebelum dimanfaatkan oleh pengguna. Tegangan energi terbarukan biasanya tersimpan kedalam baterai atau aki sebelum di konversi menggunakan inverter, tegangan energi terbarukan seperti panel surya, kincir dan sebagainya umumnya memiliki kapasitas \pm 12 Volt DC. Tegangan itulah yang kemudian dikonversi seperti tegangan serah 12 Volt menjadi arus bolak-balik (alternating current) sebesar 220 Volt dan dapat langsung dimanfaatkan atau dihubungkan dengan peralatan listrik sesuai dengan Daya yang dihasilkannya. Dalam pembuatannya, inverter membutuhkan beberapa komponen elektronika seperti mosfet, scr, transformator dan komponen lainnya serta pembangkit PWM seperti pemanfaatan mikrokontroler Arduino.

\section{TINJAUAN PUSTAKA}

1. KONVERTER DC KE AC (INVERTER)

Inverter adalah converter DC (Direct Current) ke AC (Alternating Curent) yaitu rangkaian pengubah tegangan DC menjadi tegangan AC baik dalam bentuk gelombang sinus, gelombang kotak, sinus modifikasi dan segi tiga. Gambar 1 memperlihatkan cara kerja dari inverter

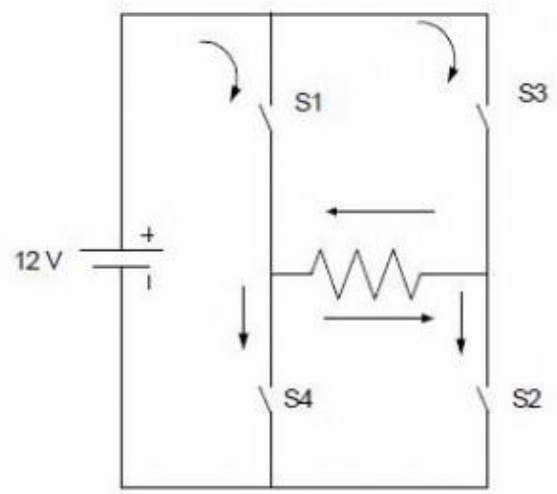

Gambar 1. Cara kerja Inverter menggunakan 4 sakelar

Bila sakelar S1 dan S2 dalam kondisi on maka akan mengalir aliran arus DC ke beban $\mathrm{R}$ dari arah kiri ke kanan, jika yang hidup adalah sakelar S3 dan S4 maka akan mengalir aliran arus DC ke beban $\mathrm{R}$ dari arah kanan ke kiri. Inverter biasanya menggunakan rangkaian modulasi lebar pulsa (pulse width modulation - PWM) dalam proses conversi tegangan DC menjadi tegangan $\mathrm{AC}$

\section{ARDUINO UNO}

Arduino Uno adalah board mikrokontroler berbasis ATmega328 (datasheet). Arduino digunakan untuk pembangkit pulsa, pulsa yang dihasilkan akan memicu switch pada rangkaian inverter untuk bekerja. 


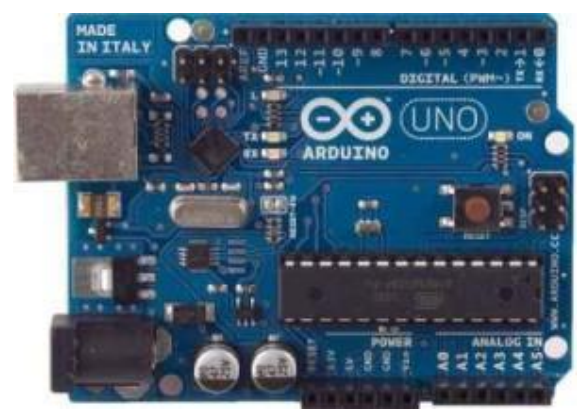

\section{SOFTWARE SIMULASI}

Dalam penelitian ini, penulis menggunakan aplikasi simulasi berupa aplikasi yang dapat membuat skematik dan melakukan simulasi layaknya seperti nyata. Ada beberapa aplikasi simulasi seperti :

1. LiveWire

2. Electronics Workbench (EWB)

3. NI Multisim

4. Fritzing

5. Autodesk Circuits

6. Proteus ISIS

Proteus ISIS merupakan aplikasi yang saat ini menjadi yang terbaik menurut penulis, karena library yang lengkap dan dapat mensimulasikan rangkaian serta dilengkapi dengan text editor yang bisa digunakan untuk programming mikrokontroler dan pembuatan PCB layout.

\section{METODE PENELITIAN}

Metode penelitian yang penulis gunakan adalah metode simulasi dimana desain dan analisis menggunakan aplikasi simulasi, diharapkan desain terbaik yaitu output yang diinginkan menjadi prototype untuk dibuat atau direkomendasikan. Metode simulasi ini dibagi kedalam tiga kegiatan :

1. Desain inverter tidak terkendali dan menganalisis keluarannya

2. Memprogram arduino uno agar pin output arduio sesuai dengan kebutuhan desain dan

3. Menggunakan arduino uno sebagai pembangkit PWM untuk inverter terkendali setengah jembatan dan jembatan penuh.
Untuk mendukung penelitian, penulis memerlukan beberapa tools dalam mendesain dan menganalisis inverter satu fasa ini, yaitu :

1. Satu unit laptop atau komputer

2. Aplikasi Proteus 8.1 Profesional untuk aplikasi simulasi

3. Library Arduino untuk Aplikasi

Proteus 8.1 Profesional

4. Arduino IDE sebagai aplikasi pemograman yang dapat menkonversikan ke bahasa mesin (hexadesimal / *.hex)

Langkah selanjutnya dapat ditunjukkan oleh diagram alir berikut :

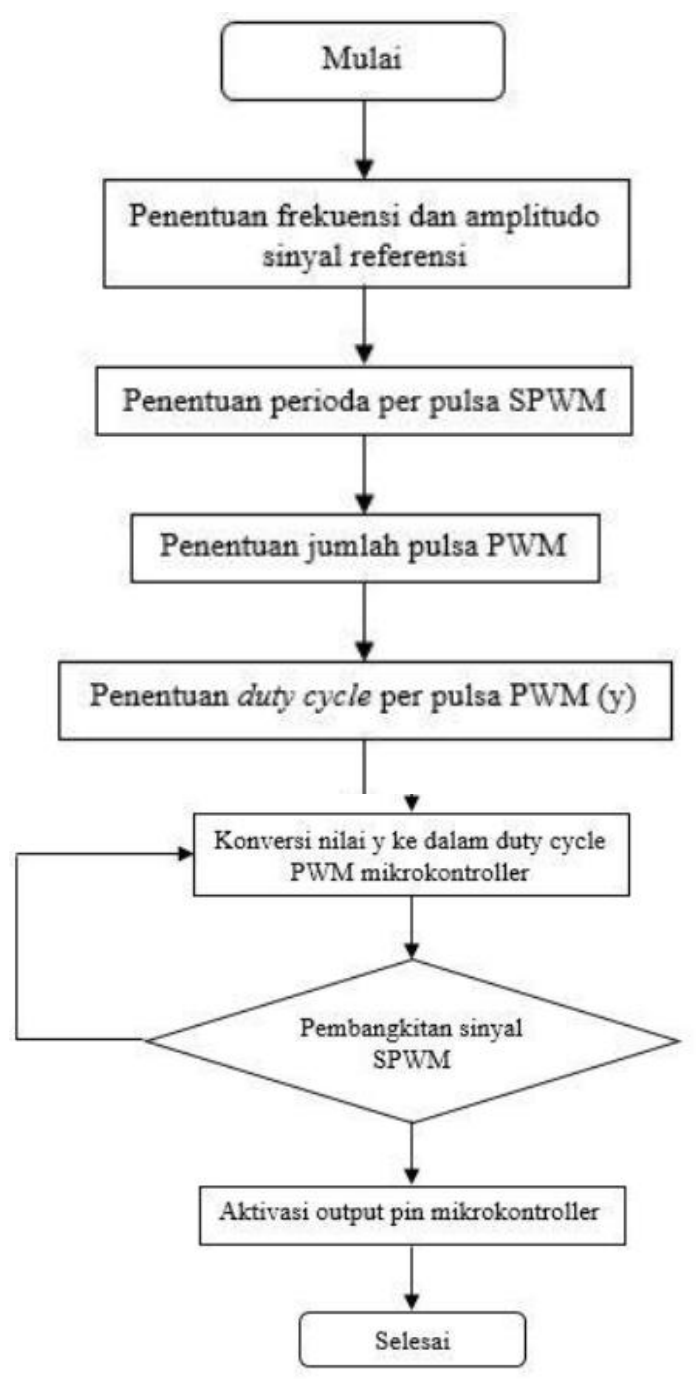

4. HASIL DAN DATA 
Percobaan inverter 1 fasa sederhana yang diuji coba pertama adalah rangkaian inverter 1 fasa tanpa pengendali dengan skematik berikut:

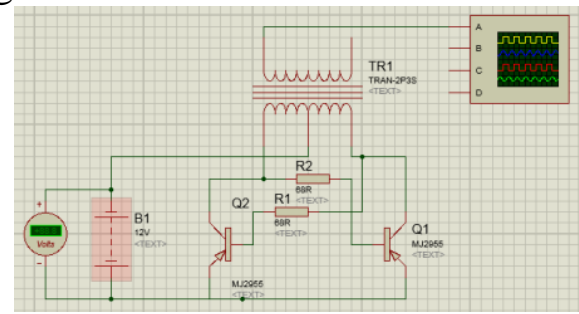

Dalam experimen, induktansi primer trafo diset $100 \mathrm{H}$ sedangkan induktansi sekunder $1.1 \mathrm{H}$ atau

Output yang dihasilkan adalah :

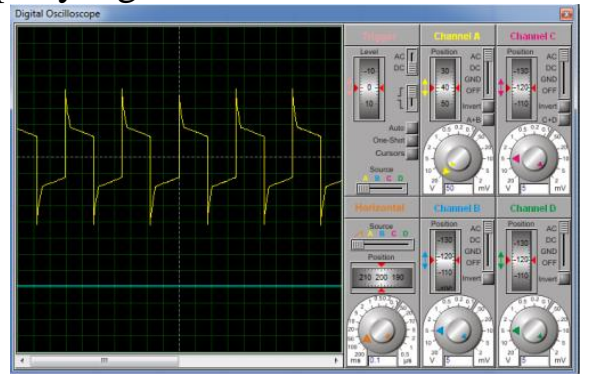

Dari hasil diperoleh :

Tegangan output $\quad \mathrm{Vp}=$ banyak div dari 0 ke puncak $*$ volt/div

$$
\begin{aligned}
& \mathrm{Vp}=4,2 * 50 \mathrm{~V} \\
& \mathrm{Vp}=210 \mathrm{~V}
\end{aligned}
$$

Vpp adalah tegangan puncak positif ke puncak negatif, sementara tegangan puncak atau Vp adalah 1/2 Vpp yaitu $210 \mathrm{~V}$.

Frekuensi: $\quad f=1 / T$

Dimana: $\quad \mathrm{T}=$ banyaknya div dalam satu perioda $*$ time/div

$$
\begin{aligned}
& \mathrm{T}=3,5 * 0,1 \mathrm{~ms} \\
& \mathrm{~T}=0,35 \mathrm{us}
\end{aligned}
$$

Sehingga

$$
\begin{aligned}
& \mathrm{f}=1 \text { detik } / 0,35 \mathrm{~ms} \\
& \mathrm{f}=1000 / 0,4 \\
& \mathrm{f}=2857,14 \mathrm{~Hz}
\end{aligned}
$$

Rangkaian inverter 1 fasa sederhana adalah inverter 1 fasa tidak terkendali dimana pulsa yang dihasilkan diperoleh dari umpan balik kolektor transistor satu ke basis transistor lainnya sehingga untuk membuat inverter dengan frekuensi yang diinginkan diperlukan pembangkit pulsa yang dapat dikendalikan sesuai kebutuhan.
Berikutnya experimen menggunakan pengendali yaitu menggunakan arduino sebagai pembangkit pulsa, dalam eksperimen ini penulis menggunakan dua perintah/koding yaitu pembangkit pulsa (tanpa menggunakan PWM) dan menggunakan PWM. Berikut koding untuk pembangkit pulsa tanpa menggunakan PWM :

int fasa_1a $=9$;

//Pin 9 untuk Q1 nantinya

int fasa_1b $=10$;

//pin 10 untuk Q2 nantinya

void $\operatorname{setup}()\{$

//kedua pin berfungsi sebagai output Arduino sehingga :

pinMode (fasa_1a, OUTPUT);

pinMode (fasa_1b, OUTPUT);

\}

void $\operatorname{loop}()\{$

// pembangkit pulsa seperti flip-flop dengan delay $10 \mathrm{~ms}$ dimana frekuensi yang diinginkan $1000 \mathrm{~ms} / 50 \mathrm{~Hz}$ diperoleh waktu $20 \mathrm{~ms}$ dan $20 \mathrm{~ms} / 2$ pin sehingga masing-masing pin $10 \mathrm{~ms}$ sebagai berikut : digitalWrite (fasa_1a, LOW); digitalWrite (fasa_1b, HIGH); delay(10);

digitalWrite (fasa_1a, HIGH); digitalWrite (fasa_1b, LOW); delay(10); \}

Dari koding diatas, diperoleh output pada pin 9 dan 10 sebagai berikut :

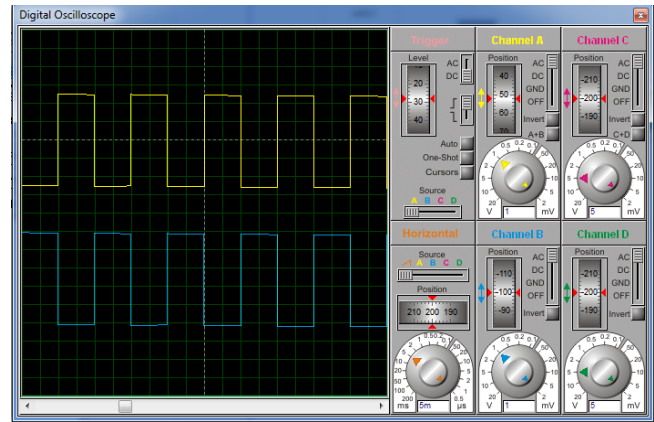


Frekuensi yang dihasilkan $1 / \mathrm{T}$ dimana $\mathrm{T}=$ $4 \operatorname{div} * 5 \mathrm{~ms}=20 \mathrm{~ms}$ sehingga $1000 \mathrm{~ms} / 20 \mathrm{~ms}=50 \mathrm{~Hz}$, sedangkan tegangan yang dihasilkan adalah $2,5 \mathrm{div} *$ $1 \mathrm{v}=2,5 \mathrm{~V}_{\mathrm{p}}$ atau $5 \mathrm{~V}_{\mathrm{pp}}$

berikut :

Untuk koding PWM adalah sebagai

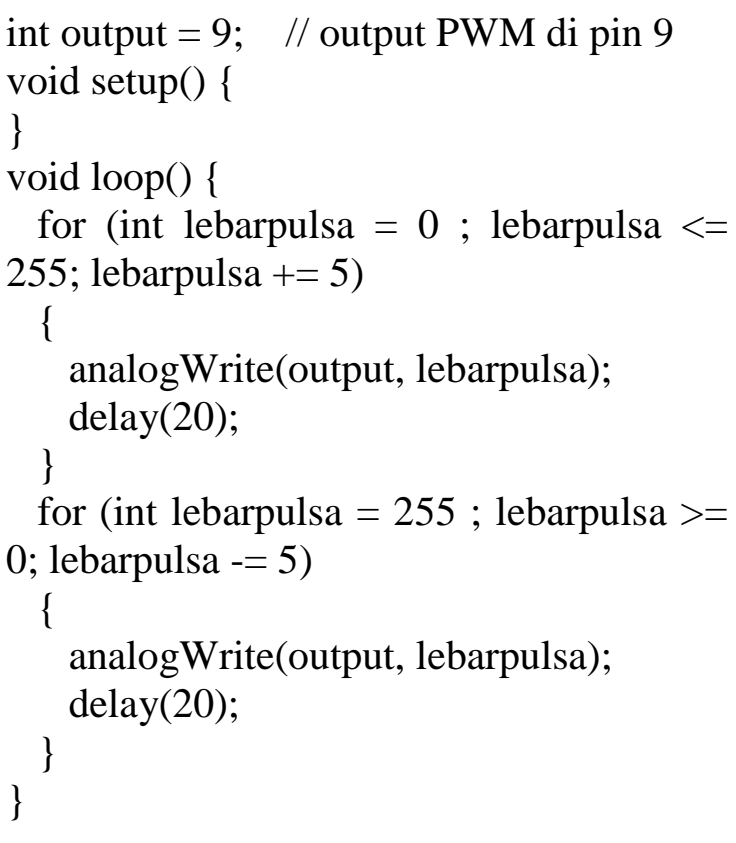

Pin 9 atau output adalah nilai lebar pulsa dimana nilai akan berubah dari 0 (nilai terendah atau 0v) sampai dengan 255 (nilai maksimal atau 5v) selama 20ms dan kebalikannya yaitu dari 255 (nilai maksimal atau 5v) ke 0 (nilai terendah atau Ov) dengan waktu $20 \mathrm{~ms}$ dan kejadian tersebut dilakukan secara terus menerus sehingga menghasil output :

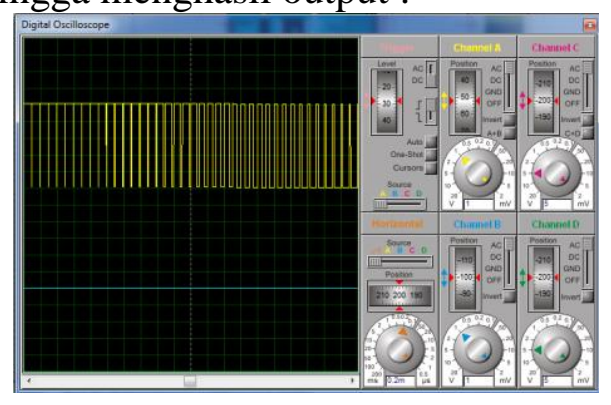

a. Inverter Satu Fasa setengah Jembatann Skema inverter satu fasa setengah Jembatan sebagai berikut :

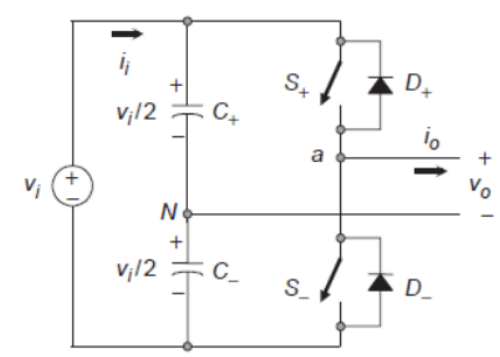

Saklar dalam skema diatas diganti dengan Mosfet dan disimulasikan ke Proteus ISIS sehingga :

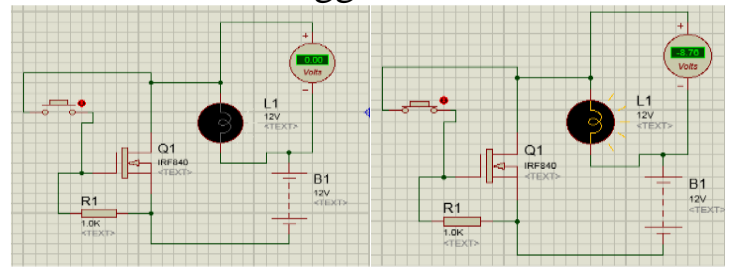

Bila gate mendapatkan tegangan dengan cara menghubungkan switch ke positif maka lampu hidup dan sebaliknya mati. Dari ujicoba diatas, dibuatlah rangkaian setengah jembatan dengan sumber ujicoba menggunakan saklar :

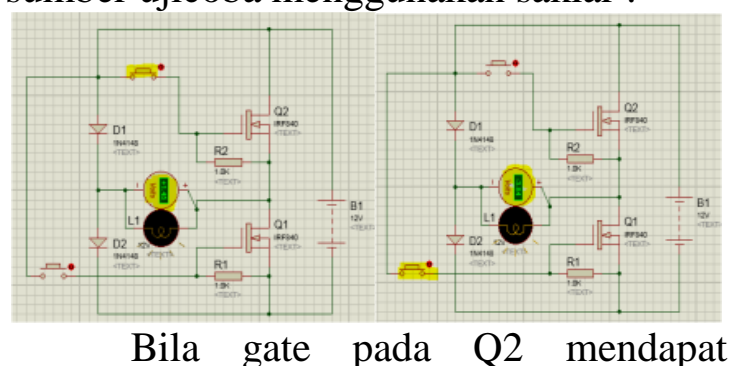
masukan maka output positif dan bila gate Q1 yang mendapat masukan maka output bernilai negatif. Dari ujicoba diatas, rangkaian inverter setengah jembatan bekerja dengan baik namun bila tegangan yang mengalir pada Gate Q1 atau Q2 3V atau kurang maka mosfet tidak bekerja karena sesuai datasheet IRF840 yaitu minimal $10 \mathrm{~V}$

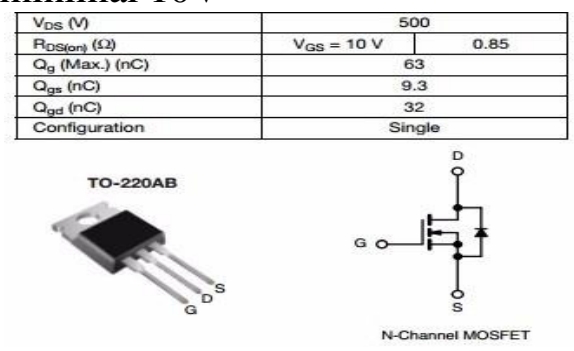

Dari experimen menggunakan simulasi terbukti bahwa mosfet tidak bekerja optimal disaat tegangan yang diberikan ke Gate Mosfet sebesar 3V : 


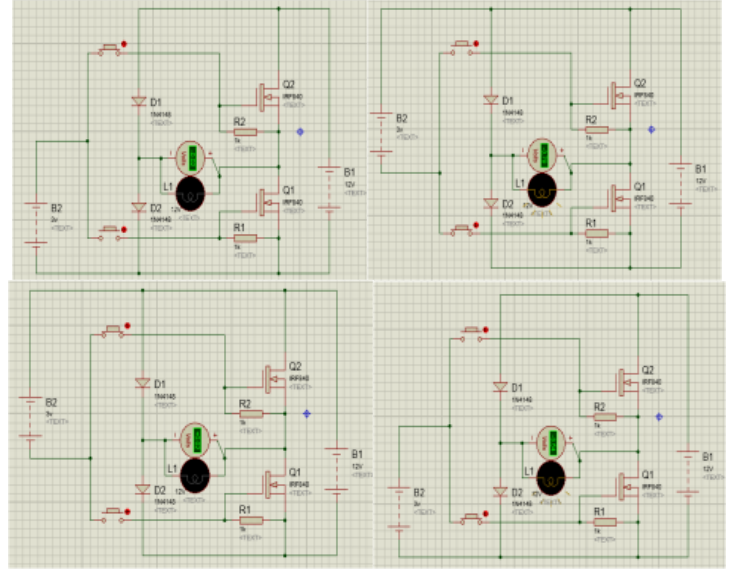

Tegangan yang keluar dari Arduino Uno sebagai pembangkit Pulsa tidak lebih dari $5 \mathrm{~V}$ atau rata-rata $3 \mathrm{~V}$, sehingga diperlukan gate drive dimana sinyal yang dikeluarkan oleh Arduino di baca dan tegangan yang ditentukan dilewati. Gate drive yang digunakan adalah IR2112, berikut rangkaian dan hasil ujicoba IR2112:

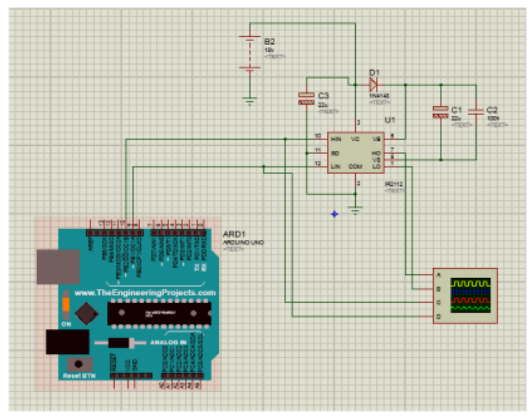

Output Arduino yaitu Pin 9 dan 10 dihubungkan ke High Input atau Hin dan pin satu lagi ke Low Input atau Lin. Rangkaian minimum Gate Drive IR2112 dipenuhi dan tegangan yang diberikan adalah 12V. Dari hasil ujicoba, High Output atau Ho dan Low Output atau Lo menghasilkan tegangan lebih besar tanpa terjadinya pergeseran sudut pulsa sehingga IR2112 mampu menaikkan tegangan keluaran arduino uno seperti hasil berikut :

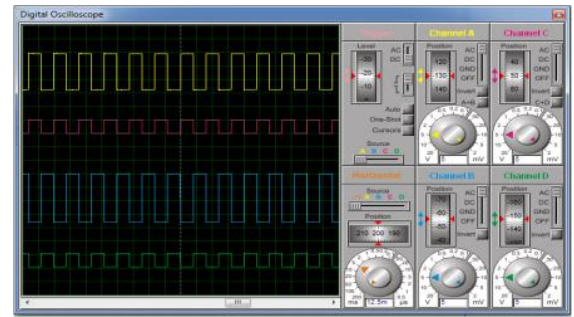

Selanjutnya output Gate Drive diteruskan ke Gate Mosfet, mosfet yang digunakan dalam simulasi adalah IRF840 dengan rangkaian berikut :

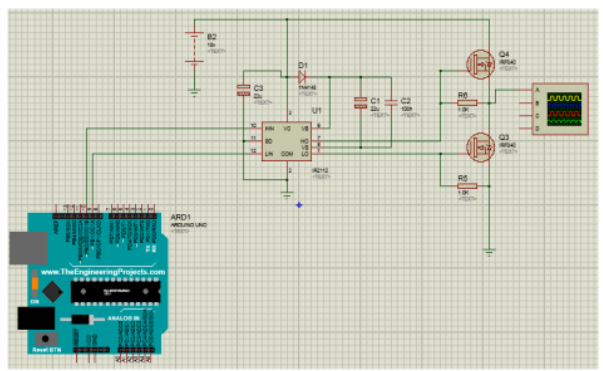

Dari hasil simulasi diperoleh keluaran sebagai berikut :

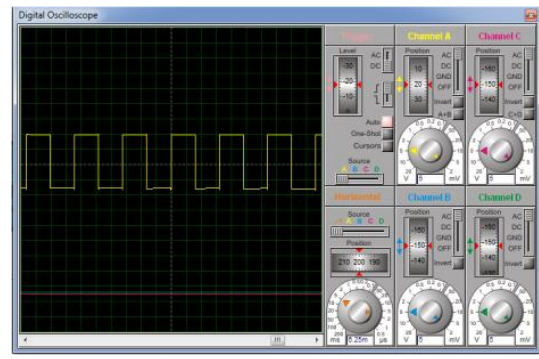

Inverter satu fasa dengan gelombang persegi $50 \mathrm{~Hz}$, selanjutnya memberi filter pada output agar gelombang persegi menjadi sinus murni. Untuk mendapatkan berapa besarnya induktif dan kapasitif yang dibutuhkan, kita dapat menggunakan rumus berikut :

$$
f=\frac{1}{2 \pi \sqrt{L C}}
$$

Untuk Filter $50 \mathrm{~Hz}$ dengan kapasitor 470uf maka induktansi yang dibutuhkan $0,0010387 \mathrm{H}$ atau $10,387 \mathrm{mH}$ sehingga diperoleh rangkaian sebagai berikut :

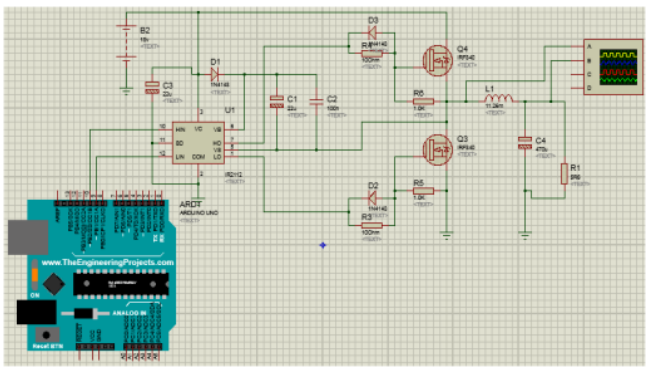

Berdasarkan hasil simulasi diperoleh output sebagai berikut : 


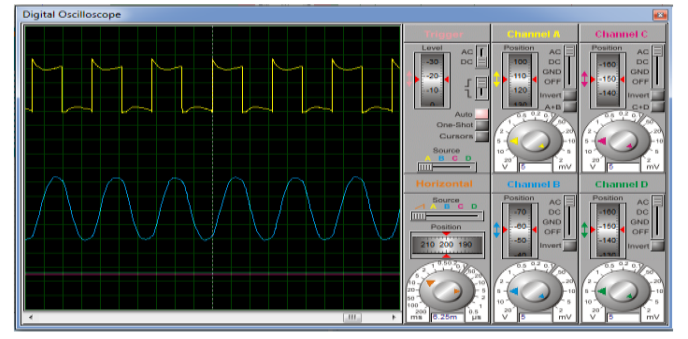

Gelombang atas adalah output sebelum masuk ke filter dimana filter mempengaruhi gelombang persegi menjadi tidak persegi sedangkan output dari filter adalah gelombang sinus sehingga experimen inverter satu fasa setengah gelombang berhasil sesuai dengan harapan.

b. Inverter Satu Fasa Jembatan Penuh

Selanjutnya experimen jembatan penuh, secara skema anatara setengah jembatan dan jembatan penuh terletak pada pengedali dimana peran dioda digantikan oleh mosfet sehingga 4 mosfet yang mengatur waktu on dan off seperti berikut:

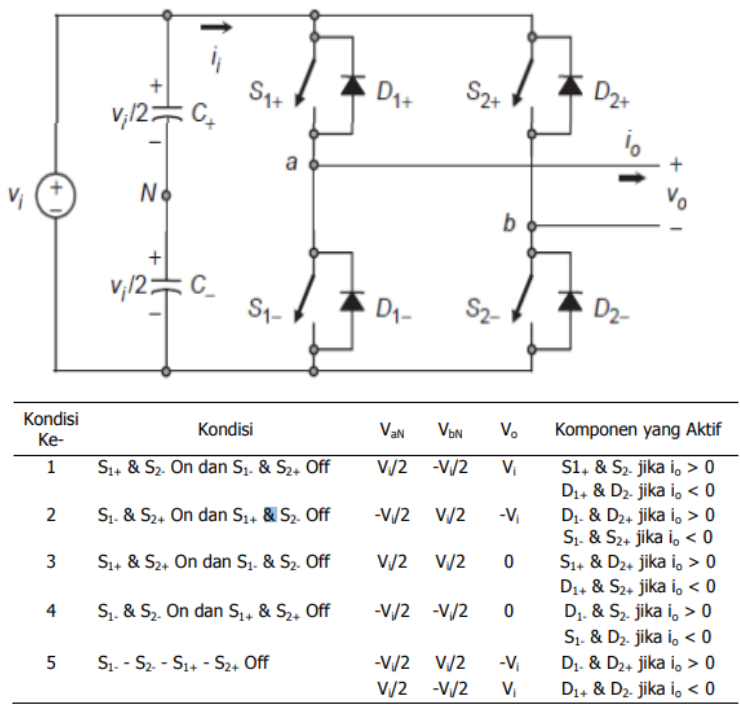

Berdasarkan tabel diatas, berikut desain rangkaiannya :

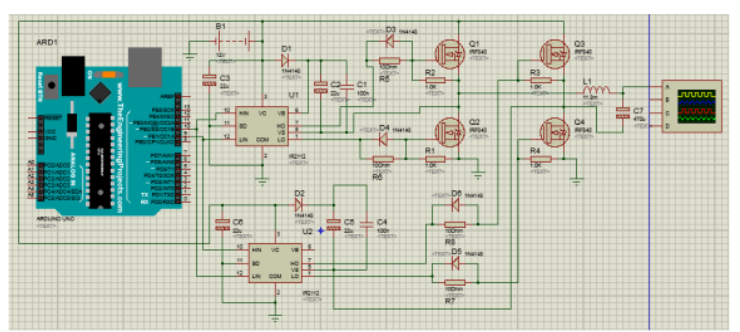

Output arduino tidak dirubah namun pin arduino untuk Hin pada GateDrive1 menjadi Lin pada GateDrive2 dan sebaliknya agar fungsi mosfet sesuai tabel diatas. Dari hasil simulasi diperoleh hasil keluaran inverter satu fasa dengan metode jembatan penuh yaitu :

1. Frekuensi yang dihasilkan tetap sama dengan inverter satu fasa setengah jembatan

2. Tegangan 2 kali lipa dibandingkan inverter satu fasa setengah jembatan

3. Gelombang sinus lebih baik dari inverter satu fasa setengah jembatan Berikut output hasil simulasi :

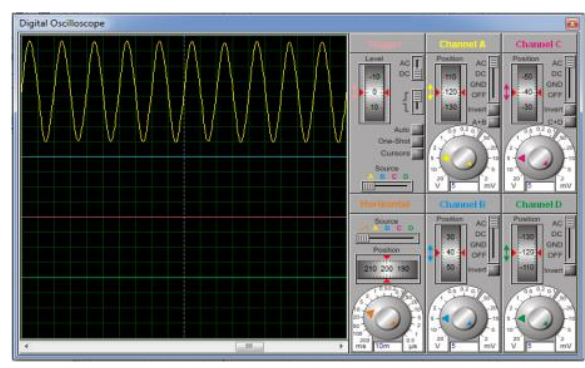

\section{KESIMPULAN DAN SARAN}

\section{Kesimpulan}

Dari uraian diatas, penulis dapat menyimpulkan bahwa :

1. Software simulasi yang dapat digunakan diantaranya : LiveWire, Electronics Workbench (EWB), NI Multisim, Fritzing, Autodesk Circuits dan Proteus ISIS. Proteus ISIS dipilih karena library yang lengkap, simulasi dan dilengkapi dengan text editor yang digunakan untuk programming mikrokontroler.

2. Inverter satu fasa tidak diberi kendali menhasilkan frekuensi yang tidak dapat diatur sedangkan inverter satu fasa menggunakan pengendali menhasilkan keluaran dengan frekuensi yang dapat diatur sesuai dengan keinginan

3. Output inverter satu fasa tidak menggunakan kendali yaitu 2857,14 $\mathrm{Hz}$ sedangkan yang terkendali yaitu $50 \mathrm{~Hz}$. 
4. Perbandingan antara inverter setengah jembatan dan jembatan penuh dari sisi output terlihat pada tegangan yang dihasilkan inverter jembatan penuh (2 kali lipat dari setengah jembatan) karena saat setengah gelombang positif dibangitkan oleh 1 mosfet untuk setengah jembatan dan 2 mosfet untuk jembatan penuh dan sebaliknya dengan frekuensi yang sama yaitu $50 \mathrm{~Hz}$

\section{Saran}

Untuk mendapatkan hasil maksimal dari penelitian ini, desain inverter satu fasa yang direkomendasikan di rangkai dan diukur menggunakan osiloskop untuk dibandingkan dengan hasil simulasi.

\section{DAFTAR PUSTAKA}

[1] Lalu Riza Aliyan, Rini Nur Hasanah, M. Aziz Muslim, "Design of Inverter with Less Harmonics using BuckBoost Converter and SPWM Method," dalam International Conference on Electrical Engineering, Computer Science and Informatics, Yogyakarta, 2014.

[2] C. Dr John Cheng, "IEEE Standard 519-2014: Compliances, Updates, Solutions, and Case Studies," Schneider Electricity, France, 2014.

[3] R. Safitri, "Desain Sinkronisasi Inverter pada Grid Satu Fasa Metode Zero Crossing," Universitas Syiah Kuala, Banda Aceh, 2016.

[4] Aswardi, "Konverter DC-AC 3 Fasa (Three Phase Inverter) Elektronika Daya," Universitas Negeri Padang, Padang, 2009.

[5] W. A. Hamed, "Power Electronic Inverter Circuits," University of Khartoum, Khartoum, 2013.

[6] A. Elbanhawy, "edn," 22 November 2001. [Online]. Available: http://www.edn.com/design/componen ts-and-packaging/4341997/A-simpleguide-to-selecting-power-MOSFETs. [Diakses 12 April 2017].
[7] R. Kennel, "Power Electronics : Exercise Pulse Width Modulation," Technische Universität München, München, 2013.

[8] B. Malik, "Microcontrollers Lab," 1 Agustus 2014. [Online]. Available: http://microcontrollerslab.com/spwmgeneration-using-pic16f877amicrocontroller/. [Diakses 7 Maret 2017].

[9] Administrator, "eprojectszone," 2016 Agustus 21. [Online]. Available: http://www.eprojectszone.com/2016/0 $8 / 21 /$ how-to-generate-a-sine-wavefrom-arduino-or-atmega-328/. [Diakses 17 Maret 2017].

[10] Administrator, "Wikipedia," 2001. [Online]. Available: https://en.wikipedia.org/wiki/LC_circ uit. [Diakses 18 November 2017].

[11] A.Z.M. Shahriar Muttalib, Ahmed Mortuza Saleque, Nawjif Md. Anamul Hasan, "Design and Simulation of an Inverter with High Frequency Sinusoidal PWM Switching Technique for Harmonic Reduction in a Standalone/Utility Grid Synchronized Photovoltaic System," IEEE International Conference on Informatics, Electronics \& Vision, vol. 12, pp. 1169-1173, 2012.

[12] Administrator, "Arduino Uno (USA Only) \& Genuino Uno (Outside USA)," Arduino, [Online]. Available: https://www.arduino.cc/en/Main/Ardu inoBoardUno. [Diakses 10 Oktober 2016].

[13] Administrator, "Engineers Garage," [Online]. Available: https://www.engineersgarage.com/em bedded/avr-microcontrollerprojects/phase-correct-pwm-modetimer-circuit. [Diakses 2017 Maret 15].

[14] H. Andri, "Inverter Satu Fasa Sinkron Berbasis Digital Phase Locked Loop," Universitas Indonesia, Depok, 2012. 